2015

Overshadowing by fixed- and variable-duration stimuli.

Bonardi, C

http://hdl.handle.net/10026.1/10807

10.1080/17470218.2014.960875

Q J Exp Psychol (Hove)

All content in PEARL is protected by copyright law. Author manuscripts are made available in accordance with publisher policies. Please cite only the published version using the details provided on the item record or document. In the absence of an open licence (e.g. Creative Commons), permissions for further reuse of content should be sought from the publisher or author. 


\section{PROOF COVER SHEET}

Author(s): Dómhnall J. Jennings

Article Title: Overshadowing by fixed- and variable-duration stimuli

Article No: $\quad$ PQJE960875

Enclosures: $\quad$ 1) Query sheet

2) Article proofs

Dear Author,

1. Please check these proofs carefully. It is the responsibility of the corresponding author to check these and approve or amend them. A second proof is not normally provided. Taylor \& Francis cannot be held responsible for uncorrected errors, even if introduced during the production process. Once your corrections have been added to the article, it will be considered ready for publication.

Please limit changes at this stage to the correction of errors. You should not make trivial changes, improve prose style, add new material, or delete existing material at this stage. You may be charged if your corrections are excessive (we would not expect corrections to exceed 30 changes).

For detailed guidance on how to check your proofs, please paste this address into a new browser window: http://journalauthors.tandf.co.uk/production/checkingproofs.asp

Your PDF proof file has been enabled so that you can comment on the proof directly using Adobe Acrobat. If you wish to do this, please save the file to your hard disk first. For further information on marking corrections using Acrobat, please paste this address into a new browser window: http:// journalauthors.tandf.co.uk/production/acrobat.asp

2. Please review the table of contributors below and confirm that the first and last names are structured correctly and that the authors are listed in the correct order of contribution. This check is to ensure that your name will appear correctly online and when the article is indexed.

\begin{tabular}{|l|l|l|l|l|}
\hline Sequence & Prefix & Given name(s) & Surname & Suffix \\
\hline 1 & & Charlotte & Bonardi & \\
\hline 2 & & Esther & Mondragón & \\
\hline 3 & & Ben & Brilot & \\
\hline 4 & & Dómhnall J. & Jennings & \\
\hline
\end{tabular}


Queries are marked in the margins of the proofs, and you can also click the hyperlinks below.

\section{AUTHOR QUERIES}

\section{General points:}

1. Permissions: You have warranted that you have secured the necessary written permission from the appropriate copyright owner for the reproduction of any text, illustration, or other material in your article. Please see http://journalauthors.tandf.co.uk/permissions/usingThirdPartyMaterial.asp.

2. Third-party content: If there is third-party content in your article, please check that the rightsholder details for re-use are shown correctly.

3. Affiliation: The corresponding author is responsible for ensuring that address and email details are correct for all the co-authors. Affiliations given in the article should be the affiliation at the time the research was conducted. Please see http://journalauthors.tandf.co.uk/preparation/ writing.asp.

4. Funding: Was your research for this article funded by a funding agency? If so, please insert 'This work was supported by <insert the name of the funding agency in full>', followed by the grant number in square brackets '[grant number $\mathrm{xxxx}$ ]'.

5. Supplemental data and underlying research materials: Do you wish to include the location of the underlying research materials (e.g. data, samples or models) for your article? If so, please insert this sentence before the reference section: 'The underlying research materials for this article can be accessed at $<$ full link $>$ / description of location [author to complete]'. If your article includes supplemental data, the link will also be provided in this paragraph. See $<$ http://journalauthors.tandf.co.uk/preparation/multimedia.asp $>$ for further explanation of supplemental data and underlying research materials.

6. The CrossRef database (www.crossref.org/) has been used to validate the references. Changes resulting from mismatches are tracked in red font.

\begin{tabular}{|c|c|}
\hline QUERY NO. & QUERY DETAILS \\
\hline AQ1 & Please provide the department, city and country for this affiliation. \\
\hline AQ2 & $\begin{array}{l}\text { The reference "Wagner, } 1981 \text { " is cited in the text but is not listed in the references list. } \\
\text { Please either delete in-text citation or provide full reference details following journal } \\
\text { style. }\end{array}$ \\
\hline AQ3 & $\begin{array}{l}\text { The reference "Rescorla \& Wagner, } 1971 \text { " is cited in the text but is not listed in the } \\
\text { references list. Please either delete in-text citation or provide full reference details } \\
\text { following journal style. }\end{array}$ \\
\hline AQ4 & $\begin{array}{l}\text { The year for "Terrace et al., 1977" has been changed to year to "Terrace et al., 1975" } \\
\text { match the entry in the references list. Please provide revisions if this is incorrect. }\end{array}$ \\
\hline AQ5 & $\begin{array}{l}\text { Please provide the volume number and page range for reference Mondragón et al. } \\
2014 .\end{array}$ \\
\hline AQ6 & Please provide missing city for the "Pavlov, 1927" references list entry. \\
\hline AQ7 & $\begin{array}{l}\text { The Reference "Kamin, 1969; Mackintosh, 1976; Witnauer et al., 2012" are listed in } \\
\text { the references list but is not cited in the text. Please either cite the reference or remove } \\
\text { it from the references list. }\end{array}$ \\
\hline
\end{tabular}




\begin{tabular}{|c|c|}
\hline QUERY NO. & QUERY DETAILS \\
\hline AQ8 & $\begin{array}{l}\text { Running head ok, or should it be "Overshadowing and stimulus distribution", as on } \\
\text { CATs ms. sheet? }\end{array}$ \\
\hline AQ9 & Give spelling out of BMSU in author note. \\
\hline AQ10 & Please provide the department for this affiliation. \\
\hline AQ11 & $\begin{array}{l}\text { Introduction heading deleted in accordance with APA guidelines (APA6: } 2.05 \text {, p. 27; } \\
3.03 \text {, p. 63). }\end{array}$ \\
\hline AQ12 & Please give year for Mackintosh. \\
\hline AQ13 & RET: Please give spelling out. \\
\hline AQ14 & Correct for sense as rewritten? \\
\hline AQ15 & Displayed list changed to run-in list here. OK? \\
\hline AQ16 & 032 correct as changed to $.032 ?$ \\
\hline AQ17 & Spelling out—responses per minute for rpm-correct as inserted? \\
\hline AQ18 & $\begin{array}{l}\text { Zeros before points ok as inserted here? [zeros in decimal fractions: "Use a zero before } \\
\text { the decimal point with numbers that are less than } 1 \text { when the statistic can exceed } 1 \ldots \\
\text { Do not use a zero before a decimal fraction when the statistic cannot be greater than } 1 \\
\text { (e.g., correlations, proportions, and levels of statistical significance)" (APA } 6,4.35 \text {, p. } \\
\text { 113)] }\end{array}$ \\
\hline AQ19 & Please insert zeros before points where necessary [see AQ10]. \\
\hline AQ20 & Correct as rewritten? \\
\hline AQ21 & Zeros before points ok as inserted here? [see AQ10]. \\
\hline AQ22 & Insert zeros before points where necessary [see AQ10]. \\
\hline AQ23 & "conditions based": Should this be "condition is based"? \\
\hline AQ24 & Please give spelling out of SSCC. \\
\hline AQ25 & Figure 1: Explanation of letters correct as inserted? \\
\hline AQ26 & Figure 2: Explanation of letters correct as inserted? \\
\hline AQ27 & Figure 3: Explanation of letters correct as inserted? \\
\hline AQ28 & Figure 4: Explanation of letters correct as inserted? \\
\hline AQ29 & Figure 5: Explanation of letters correct as inserted? \\
\hline AQ30 & Figure 6: Explanation of letters correct as inserted? \\
\hline AQ31 & Figure 7: Explanation of letters correct as inserted? \\
\hline AQ32 & Figure 8: Explanation of letters correct as inserted? \\
\hline AQ33 & Table 1 ok as rearranged? \\
\hline AQ34 & $\begin{array}{l}\text { Table 1: Column head OK as inserted? [Each column of a table must have a heading, } \\
\text { including the stub column or stub, which is the leftmost column of the table (APA6, } \\
5.13 \text {, p. 134)] }\end{array}$ \\
\hline
\end{tabular}




\begin{tabular}{|c|l|}
\hline QUERY NO. & \multicolumn{1}{c|}{ QUERY DETAILS } \\
\hline AQ35 & Table 1: Give units: responses per min? \\
\hline AQ36 & Table 1: Explanation of letters correct as inserted? \\
\hline AQ37 & Table 2: Table ok as rearranged? \\
\hline AQ38 & Table 2: Give units: responses per min? \\
\hline AQ39 & Table 2: Explanation of letters correct as inserted? \\
\hline
\end{tabular}




\section{How to make corrections to your proofs using Adobe Acrobat/Reader}

Taylor \& Francis offers you a choice of options to help you make corrections to your proofs. Your PDF proof file has been enabled so that you can edit the proof directly using Adobe Acrobat/Reader. This is the simplest and best way for you to ensure that your corrections will be incorporated. If you wish to do this, please follow these instructions:

1. Save the file to your hard disk.

2. Check which version of Adobe Acrobat/Reader you have on your computer. You can do this by clicking on the "Help" tab, and then "About".

If Adobe Reader is not installed, you can get the latest version free from http://get.adobe.com/reader/.

3. If you have Adobe Acrobat/Reader 10 or a later version, click on the "Comment" link at the right-hand side to view the Comments pane.

4. You can then select any text and mark it up for deletion or replacement, or insert new text as needed. Please note that these will clearly be displayed in the Comments pane and secondary annotation is not needed to draw attention to your corrections. If you need to include new sections of text, it is also possible to add a comment to the proofs. To do this, use the Sticky Note tool in the task bar. Please also see our FAQs here: http://journalauthors.tandf.co.uk/production/index.asp.

5. Make sure that you save the file when you close the document before uploading it to CATS using the "Upload File" button on the online correction form. If you have more than one file, please zip them together and then upload the zip file.

If you prefer, you can make your corrections using the CATS online correction form.

\section{Troubleshooting}

Acrobat help: http://helpx.adobe.com/acrobat.html

Reader help: http://helpx.adobe.com/reader.html

Please note that full user guides for earlier versions of these programs are available from the Adobe Help pages by clicking on the link "Previous versions" under the "Help and tutorials" heading from the relevant link above. Commenting functionality is available from Adobe Reader 8.0 onwards and from Adobe Acrobat 7.0 onwards.

Firefox users: Firefox's inbuilt PDF Viewer is set to the default; please see the following for instructions on how to use this and download the PDF to your hard drive: http://support.mozilla.org/ en-US/kb/view-pdf-files-firefox-without-downloading-them\#w_using-a-pdf-reader-plugin 
5

AQ10

AQ1

$\Lambda$

\title{
Overshadowing by fixed- and variable-duration stimuli
}

\author{
Charlotte Bonardi ${ }^{1}$, Esther Mondragón ${ }^{2}$, Ben Brilot ${ }^{3}$, and Dómhnall J. Jennings ${ }^{3}$ \\ ${ }^{1}$ School of Psychology, University of Nottingham, Nottingham, UK \\ ${ }^{2}$ Centre for Computational and Animal Learning Research \\ ${ }^{3}$ Institute of Neuroscience, Newcastle University, Newcastle, UK
}

Two experiments investigated the effect of the temporal distribution form of a stimulus on its ability to produce an overshadowing effect. The overshadowing stimuli were either of the same duration on every trial, or of a variable duration drawn from an exponential distribution with the same mean duration as that of the fixed stimulus. Both experiments provided evidence that a variable-duration stimulus was less effective than a fixed-duration cue at overshadowing conditioning to a target conditioned stimulus (CS); moreover, this effect was independent of whether the overshadowed CS was fixed or variable. The findings presented here are consistent with the idea that the strength of the association between CS and unconditioned stimulus (US) is, in part, determined by the temporal distribution form of the CS. These results are discussed in terms of time-accumulation and trial-based theories of conditioning and timing.

Keywords: Rats; Timing; Overshadowing; Associative learning; Stimulus distribution form

When a conditioned stimulus (CS) is reliably followed by an unconditioned stimulus (US), a conditioned response (CR) develops during the CS indicating that the US is anticipated. This change in behaviour has been attributed to the formation of an association between the mental representations of these two events, such that presentation of the CS can activate the representation of the US and hence elicit the CR (e.g., Mackintosh, 1975; Pearce, 1994; Pearce \& Hall, 1980; Rescorla \& Wagner, 1972; Wagner, 1981). Associations are assumed to arise from contiguity between CS and US, but the extent to which an association is strengthened by CS/US pairings is moderated by other factors. This is illustrated by the phenomenon of cue competition, of which overshadowing is one example.

\section{Associative accounts of overshadowing}

Cue competition refers to situations in which CS/ US contiguity produces varying degrees of conditioning because other cues that are present can effectively compete with the target CS for associative strength. It has been recognized as a critical feature of the associative process, as it selectively promotes learning about events that are positively correlated-and hence likely to be causally related. As the primary aim of the associative theories mentioned above is to delineate the conditions under which associations form, all offer an explanation of cue competition effects.

Perhaps the simplest example of cue competition is overshadowing, which refers to the attenuation of conditioned responding that arises if a CS is

Correspondence should be addressed to Dómhnall Jennings, Institute of Neuroscience, Newcastle University, Henry Wellcome building, Framlington Place, Newcastle, NE2 4HH, UK. E-mail: domhnall.jennings@newcastle.ac.uk

The authors would like to thank Eric Tam for helpful discussion and BMSU staff for excellent technical support.

This work was funded by the Biotechnology and Biological Sciences Research Council (BBSRC). 
conditioned in compound with some other cue, rather than being conditioned alone. For example, according to both Rescorla and Wagner (1972) and Pearce and Hall (1980), CS/US contiguity fails to

produce conditioning when the US is fully predicted, ${ }^{1}$ and the total associative strength that may condition to a given US is limited; thus the more associative strength is acquired by the overshadowing stimulus, the greater an overshadowing effect it will produce. Mackintosh's mechanism is slightly more complex, only predicting overshadowing if the overshadowing stimulus conditions more than the target $\mathrm{CS}$ on the first trial. Nonetheless, if overshadowing occurs then this model also predicts that it will increase with the associative strength of the overshadowing stimulus (see also Wagner, 1981).

\section{Associative models and time}

These associative models rely on the occurrence of trials, during which a CS is presented that may or may not be paired with a US. A trial is a potential learning experience for the subject that does not refer to the duration of the constituent events and so conveniently allows the same description of learning to be applied to CSs and USs that are milliseconds or minutes in duration. Associative models of this type have thus been referred to as trial based (cf. Bouton \& Sunsay, 2003) and can be distinguished from alternative associative accounts that stress a more performance-focused approach and explain cue competition as a retrieval deficit (e.g., comparator theory: Denniston, Savastano, \& Miller, 2001) and from those that employ associations as an explanatory tool, but for which associations are not the primary focus (e.g., packet theory: Kirkpatrick, 2002).

Trial-based theories have tended to ignore the effects of temporal factors on the conditioning process and suppose that properties of the CS such as its duration do not affect the course of learning. Such theories also typically take the magnitude or rate of the CR computed over the entire CS (typically expressed as responses per minute for purposes of comparison) as the primary measure of learning, ignoring variations in the $\mathrm{CR}$ at different points of the CS with different proximity to US delivery. Yet the importance of time in conditioning has been recognized since Pavlov (1927), who observed that maximum conditioned responding occurs at the end of temporally extended CSs-inbibition of delay. Others have reported a systematic relationship between the relative durations of the CS and intertrial interval (ITI) and both the speed with which the CR develops (Gibbon, Baldock, Locurto, \& Terrace, 1977) and its final asymptotic rate (e.g., Lattal, 1999; Terrace, Gibbon, Farrell, \& Baldock, 1975; but see Holland, 2000; Kirkpatrick \& Church, 2000). Moreover, in the peak procedure a $\mathrm{CS}$ conditioned at a fixed duration is tested on longer, peak trials, on which the rate of the CR increases gradually until the point of US delivery and then declines again — suggesting that animals can time US occurrence.

More recent work has explored both the degree to which the lawful relationships between CS and ITI durations and the CR may be explained in terms of trial-based theories and the effect of other temporal factors on conditioning within a trial-based associative framework (e.g., Bouton \& Sunsay, 2003; Holland, 2000). Others have used trial-based associative theories as a starting point for development of real-time accounts that explicitly propose how associations can convey temporal information, by regarding each trial as a series of real-time learning episodes (e.g., Kutlu \& Schmajuk, 2012; Sutton \& Barto, 1987; Vogel, Brandon, \& Wagner, 2002). ${ }^{2}$

\section{Nonassociative accounts of conditioning: Time-accumulation models}

A different approach to this issue has led to the development of conditioning accounts that

\footnotetext{
${ }^{1}$ According to Rescorla and Wagner (1972), this failure of learning is mediated via a reduction in US processing, according to Pearce and Hall (1980), it is via a reduction in CS processing.

${ }^{2}$ These models are more accurately described as episode based rather than trial based, but share with trial-based models the assumption that learning occurs incrementally on discrete learning episodes.
} 
assume that temporal features of the conditioning episode are central to what is learned, arguing that information about the temporal properties of the environment extant during learning is obtained by accumulating information over a broad temporal window, such as an experimental session (e.g., Gallistel \& Gibbon, 2000; Gibbon \& Balsam, 1981; see also Balsam, Drew, \& Gallistel, 2010; Balsam \& Gallistel, 2009). Information about the rate of US delivery during the $\mathrm{CS}$, and also in the CS's absence, is computed, and the comparison between these two values indicates the likelihood that the CS signals the US. Once this comparison reaches a certain threshold, a decision is made to respond. This approach rejects the importance of CS/US contiguity (e.g., Balsam \& Gallistel, 2009), asserting that the decision to respond depends on information accumulated over a number of trials (although the temporal window over which this accumulation takes place is typically unspecified). Thus, in contrast to the view of the trial-based models outlined above, the trial-bytrial properties of a conditioning episode are not critical to development of the CR. Such theories have been termed time-accumulation models (cf. Bouton \& Sunsay, 2003).

Time-accumulation models can explain the orderly relationship between conditioned respond120 ing and CS and ITI durations, because of the inverse relation between interval duration and reinforcement rate. They are also integrated with an independent timing mechanism (Gibbon, Church, \& Meck, 1984), comprising a pacemaker from which pulses may be transferred to a short term memory store (STS) via a switch; at CS onset the switch starts diverting pulses into the STS until US delivery, when the stored value is transferred into long term memory. The accumulating pulses in the STS are compared with the values stored in long-term memory; once these values are sufficiently close, the decision is made to respond. Thus, although on each trial there is an abrupt transition from low to high responding, there is trial-to-trial variability in when this occurs because of inherent variability in both timing and memory systems (Gibbon et al., 1984). Thus, when averaged over many trials, these models can predict that the CR to a fixedduration CS increases gradually until the point at which the US is delivered.

\section{Time-accumulation accounts of cue competition}

Time-accumulation models thus provide an integrated explanation of conditioning and timing, leading some to argue that they should supersede trial-based associative theories, which provide neither a principled account of timing, nor quantitative predictions about the effect of temporal factors on acquisition and rate of the CR (e.g., Church \& Broadbent, 1990; Kirkpatrick \& Church, 1998; although see, e.g., Sutton \& Barto, 1987; Vogel et al., 2002). However, timeaccumulation accounts have difficulty explaining cue competition effects like overshadowing. RET, for example, appeals to a decision rule dictating that the $\mathrm{CR}$ is elicited only by the more salient CS; the fact that overshadowing often appears to be incomplete is attributed to an averaging artefact (e.g., Balsam \& Gallistel, 2009; Gallistel \& Gibbon, 2000). But this view runs contrary to much of the available empirical evidence, which suggests that overshadowing is a graded effect even in individual subjects (e.g., Kehoe, 1982; Thein, Westbrook, \& Harris, 2008)—a result that follows directly from the error-correction learning rule employed by trial-based associative models (e.g., Rescorla \& Wagner, 1971).

\section{Discriminating trial-based and time- accumulation accounts}

One way of discriminating between trial-based and time-accumulation approaches is to explore the extent to which the characteristics of individual trials affect acquisition of the CR. Time-accumulation models anticipate that in a simple conditioning procedure, as long as mean ITI and mean CS durations are equated, $\mathrm{CR}$ acquisition should be identical. Thus acquisition of the $\mathrm{CR}$ to $\mathrm{CS}$ s that either are of a fixed duration, or vary in duration from trial to trial but have the same overall mean duration as the fixed CS, should be the same. 
However, Jennings, Alonso, Mondragón, Franssen, and Bonardi (2013) reported a higher level of $\mathrm{CR}$ to a fixed than to a variable CS-a difference that persisted even when animals were tested under identical conditions. ${ }^{3}$ Jennings et al. (2013) interpreted these findings as evidence that the fixed-duration CS had acquired more associative strength than the variable CS.

As trial-based associative models by definition assume that learning occurs on a trial-by-trial basis, they have the theoretical apparatus to explain this result, provided assumptions about how the temporal properties of the CS may be conceptualized are added. For example, assume that each CS comprises a sequence of smaller elements, and that the mean duration of both fixed and variable CSs is 2 units: thus the fixed CS is 2 units on every trial, but the variable is equally likely to be 1 , 2 , or 3 units. Also assume for simplicity that only the final unit, contingent with the US, acquires associative strength. In the fixed case, only Unit 2 acquires associative strength, and as it is contingent with the US on every trial it will reach asymptote.

160 However, Units 1, 2, and 3 of the variable CS are each contingent with the US on only some trials: Specifically, Unit 1 will be reinforced on $33 \%$ of trials and nonreinforced on $66 \%$, Unit 2 will be reinforced on $33 \%$ and nonreinforced on 33\%, and Unit 3 will be reinforced on $33 \%$ of trials and never nonreinforced. This analysis requires additional assumptions about the relative speed of excitatory and inhibitory conditioning, whether or not conditioning to different stimulus elements interacts, how associative strength is computed across the entire CS, and so on; but it may perhaps be taken to illustrate how higher levels of conditioning to fixed-duration CSs could arise within this theoretical framework.

\section{Overshadowing by fixed- and variable- duration cues}

180 In summary, there is evidence that a fixed-duration CS acquires more associative strength than its variable counterpart (Jennings et al., 2013). This result is consistent with a trial-based approach, but cannot be explained by time-accumulation theories. The present experiments were designed to provide further evidence for this proposal: Jennings et al. (2013) only demonstrated differences in performance of the CR to fixed- and variable-duration CSs; however, it has long been argued that conditioned responding to a CS may not always be the best indicator of its associative strength (e.g., Hull, 1943; cf. Cole, Barnet, \& Miller, 1995; Rescorla, 1988). Many authors have argued that the ability to interfere with conditioning to other stimuli can serve as an alternative measure of conditioning to a CS (e. g., Rescorla, 1988), and so the present experiments adopted this strategy, examining the extent to which fixed and variable CSs can produce overshadowing. As noted above, trial-based associative theories predict that the degree of overshadowing increases with the associative strength of the overshadowing stimulus. It follows that if a fixed CS acquires associative strength more efficiently than a variable cue, then it should produce greater overshadowing. In contrast, time-accumulation models like RET predict that fixed- and variable-duration stimuli whose mean duration is equated should not differ in associative strength and so predict no difference in overshadowing on this basis. Moreover, their specific mechanism for cue competition asserts that whether or not overshadowing occurs depends on the cues' relative salience-which is also unaffected by whether the CS is fixed or variable. The first experiment evaluated these predictions.

\section{EXPERIMENT 1}

Three groups of animals received training with a light CS. The control groups (group C) were trained with the light alone, while the overshadowing groups were trained with the light in compound with an overshadowing stimulus, a white noise, that was of either fixed or variable duration (groups $\mathrm{Nf}$ and $\mathrm{Nv}$, respectively). Each group was further divided, such that for half of each the light was of

\footnotetext{
${ }^{3}$ They also demonstrated differences in the acquisition of the $\mathrm{CR}$, in the sense defined by time-accumulation accounts.
} 

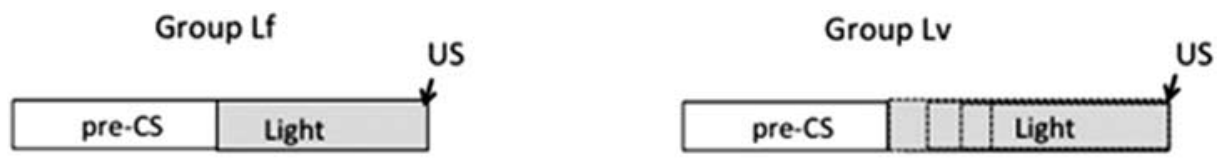

Group Nf/Lf



Group Nv/Lf

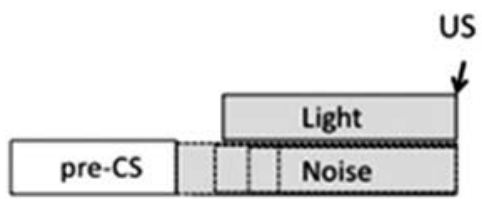

Group Nf/Lv

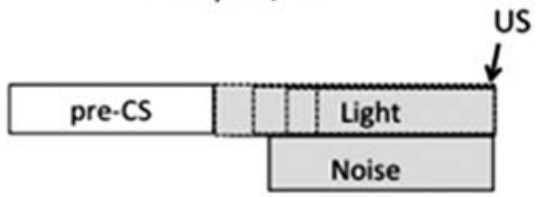

Group Nv/Lv

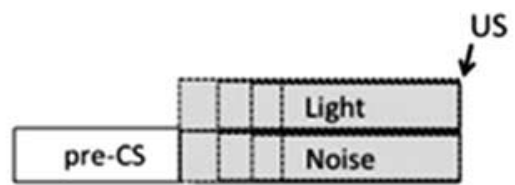

Figure 1. Schematic design of conditioned stimulus (CS) arrangement (groups $L f, N f / L f, N v / L f, L v, N f / L v$, and $N v / L v$, where $L=l i g h t, N$ $=$ noise, $f=$ fixed, and $v=$ variable). US = unconditioned stimulus.

a fixed duration, and for half it was of a variable duration. Thus groups Lf, Nf/Lf, and Nv/Lf were trained with a fixed light and groups $\mathrm{Lv}, \mathrm{Nf} / \mathrm{Lv}$, and $\mathrm{Nv} / \mathrm{Lv}$ with a variable-duration light. In groups $\mathrm{Nf} / \mathrm{Lf}$ and $\mathrm{Nv} / \mathrm{Lv}$ the noise and light had a common onset and offset, whereas in groups $\mathrm{Nf} / \mathrm{Lv}$ and $\mathrm{Nv} / \mathrm{Lf}$ they had different onsets but a common offset (see Figure 1). We anticipated that overshadowing would occur, resulting in less $\mathrm{CR}$ to the light at test in the overshadowing groups than in the control groups. But more critically, we predicted differences among the overshadowing groups-more specifically, if a fixed stimulus overshadows more effectively than a variable CS, there should be less responding to the light in groups $\mathrm{Nf} / \mathrm{Lf}$ and $\mathrm{Nf} / \mathrm{Lv}$ than in groups $\mathrm{Nv} / \mathrm{Lf}$ and $\mathrm{Nv} / \mathrm{Lv}$.

\section{Method}

\section{Subjects}

Subjects were 24 male Lister hooded rats (Harlan UK) with a mean free-feeding weight of $290 \mathrm{~g}$ (range: $275-315 \mathrm{~g}$ ). The rats were weighed daily, and their daily food ration was restricted such that their weights reduced to $85 \%$ of free-feeding levels before the start of the study. They were maintained at this level throughout training, their $85 \%$ level being adjusted weekly according to a growth curve, so that their weight increased gradually over the course of the experiment. Water was freely available in the home cages. They were maintained on a 12-hour light/dark cycle, with the lights turned on at $7 \mathrm{am}$; temperature was maintained at $21^{\circ} \mathrm{C}\left( \pm 1^{\circ}\right)$; the humidity was $60 \%( \pm 10 \%)$. There were four animals in each of the six groups (eight per experimental condition).

\section{Apparatus}

All conditioning and testing procedures were conducted in eight identical chambers $(20 \times 24 \times 30$ $\mathrm{cm})$. Each was situated in a ventilated, noiseattenuating box $(74 \times 38 \times 60 \mathrm{~cm} ; \quad$ MED Associates) and was equipped with a speaker for delivering auditory stimuli, a houselight, a food cup, and two jewel lights, one situated on each 
side of the food cup. The houselight was not employed. A speaker, located on the right side of the wall of the chamber opposite the food cup, could deliver a 74- $\mathrm{dB}$ (Scale A, measured near the food cup) white noise. A pellet dispenser (Model ENV-203) delivered 45-mg Noyes (Improved Formula A) pellets into the food cup. Each head entry into the food cup was recorded by breaking an infrared photobeam and was recorded as a response. Med-PC for Windows (Tatham \& Zurn, 1989) controlled experimental events.

\section{Procedure}

Training. All animals received four sessions of training, each comprising 40 trials in which the light was reinforced. In groups Lf and Lv the light was presented in isolation, while in the remaining groups the noise was also present; for groups $\mathrm{Nf} / \mathrm{Lf}$ and $\mathrm{Nf} / \mathrm{Lv}$ the noise was a fixed 15 $\mathrm{s}$ in duration whereas in groups $\mathrm{Nv} / \mathrm{Lf}$ and $\mathrm{Nv} / \mathrm{Lv}$ the noise was of a variable duration with a mean of $15 \mathrm{~s}$. In addition, in groups Lf, Nf/Lf, and Nv/ 250 Lf the light was of a fixed 15-s duration, while for groups $\mathrm{Lv}, \mathrm{Nf} / \mathrm{Lv}$, and $\mathrm{Nv} / \mathrm{Lv}$ the light was variable, again with a mean duration of $15 \mathrm{~s}$; the variable durations were drawn from an exponential distribution with an arithmetic mean of $15 \mathrm{~s}$. In groups $\mathrm{Nf} / \mathrm{Lf}$ and $\mathrm{Nv} / \mathrm{Lv}$ the noise and light were coextensive, whereas in groups $\mathrm{Nf} / \mathrm{Lv}$ and $\mathrm{Nv} / \mathrm{Lf}$ the noise always ended at the same time as the light, but its onset either preceded or followed that of the light (see Figure 1). Each trial comprised the CS presentation and also a $15-\mathrm{s}$ pre-CS period that immediately preceded onset of the CS (when the noise and light were asynchronous the pre-CS period immediately preceded whichever of these stimuli started first); light offset was immediately followed by the delivery of a food pellet on all trials. Each trial was separated by an intertrial interval (ITI) comprising a fixed interval of $60 \mathrm{~s}$ plus an additional variable period with a mean duration of $60 \mathrm{~s}$; this resulted in an average ITI duration of $120 \mathrm{~s}$.

Testing. The testing phase was identical to the training phase, except that there were 30 rather than 40 of the reinforced trials described in the previous section. The remaining trials in the session were nonreinforced test trials, which were all of a fixed 15-s duration. All six groups received five test trials with the light presented alone, which allowed us to evaluate the extent of the overshadowing effect. In addition the four overshadowing groups received five nonreinforced 15 -s presentations of the noise/light compound, which were used as a baseline against which overshadowing could be assessed (see below). Thus groups Lf and $L v$ received 35 trials in each test session, and groups $\mathrm{Nf} / \mathrm{Lf}, \mathrm{Nf} / \mathrm{Lv}, \mathrm{Nv} / \mathrm{Lf}$, and $\mathrm{Nv} / \mathrm{Lv}$ received 40 trials. The different types of trial were presented in a semirandom order, with the constraint that every sixth compound trial was presented in a block with one noise/light and one light test trial for the overshadowing groups and with one light test trial for the control group. There were two sessions in this stage.

\section{Data analysis}

Training. The time of occurrence of each stimulus onset, stimulus termination, food delivery, and head entry response was recorded with a resolution of $10 \mathrm{~ms}$. To assess conditioning, a corrected score was employed. This was obtained by computing the mean response rate during each type of trial in each session and subtracting the mean response rate from the pre-CS periods in that session. In groups $\mathrm{Nv} / \mathrm{Lf}$ and $\mathrm{Nf} / \mathrm{Lv}$, noise and light were not coextensive. Thus, so that responding could be evaluated under the same stimulus conditions in all four overshadowing groups, data are reported only during the time interval when both stimuli were being presented (which was on average shorter than $15 \mathrm{~s}$ ).

To confirm that the baseline pre-CS rates from which the corrected scores were derived did not differ (as differences would compromise interpretation of the corrected response rates), a corresponding analysis of pre-CS rates was also conducted.

Test. The test data were pooled across both test sessions. The degree to which conditioning to the light was overshadowed was determined by examining (a) corrected rates of responding on light 
AQ15 test trials, and (b) an overshadowing ratio. The ratio $\curlywedge \quad$ was intended as a better control for between-subject variability than correcting for pre-CS responding, as pre-CS response rates were close to floor. The 275 overshadowing ratio took the form $a /(a+b)$, where $a$ was the uncorrected response rate during the light test trials, and $b$ was the uncorrected rate on the noise/light test trials; these rates were pooled over both test sessions. We employed uncorrected rates to ensure that $a$ and $b$ were both positive values, as negative values would render the ratio uninterpretable. This ratio gave a measure of the proportion of responding on training trials that was attributable to the light. If there was no overshadowing, and the light acquired all the associative strength, then responding on trials with the noise/light compound would be identical to responding on test trials with the light alone. Thus the values of $a$ and $b$ would be the same, and the value of $a /(a+b)$ would approximate .5 , but as overshadowing increased, the proportion of responding to the noise/light compound that could be attributed to the light would fall, and the ratio would drop below .5 .

In each case, analysis was also performed on the baseline scores from which these two measures were derived-pre-CS response rates for (a) and uncorrected response rates during the noise/light test trials for (b).

Timing of the noise. Timing of the noise was also evaluated, to confirm that the animals were sensitive to the different temporal properties of the fixed- and variable-duration overshadowing stimuli. The number of responses occurring in successive 1-s time bins of the noise CS was determined in a specific session or group of sessions, and the rate of responding in each bin was calculated for each rat. For the variable CS the computation of response rate took into account the number of trials on which the CS was actually present in each time bin. These response rate functions were then normalized so that each rat contributed equally to the shape of the functions regardless of its overall response rate. Thus the response rate in each time bin was divided by the summed response rate and multiplied by 100 , giving the percentage of total responses in each time bin for each subject. Then a linear function was fitted to each normalized response rate function, and the slope was determined from the best fitting linear curve for each rat (linear fits provide a good characterization of the response rate function: Jennings, Bonardi, \& Kirkpatrick, 2007; cf. Kirkpatrick \& Church, 2000). The temporal slopes were compared against a mean of zero using one-sample $t$-tests; significance was assessed after applying the Bonferroni correction to the presented $p$ value. In Experiment 1, timing data for the noise CS were derived from responding during the noise in the compound trials of the final training session, pooled for the two groups trained with a fixed-duration noise, $\mathrm{Nf} / \mathrm{Lf}$ and $\mathrm{Nf} / \mathrm{Lv}$, and also for the two groups trained with a variable noise, $\mathrm{Nv} / \mathrm{Lf}$ and $\mathrm{Nv} /$ Lv.

A significance level of $p<.05$ was adopted throughout. All data were analysed using analysis of variance (ANOVA) with overshadowing CS (noise absent, fixed, or variable) and target CS (light fixed or variable) as between-subjects factors and session as within-subjects factor; significant two-way interactions were examined with simple main effects analysis, using the pooled error term. Main effects of overshadowing CS were examined using Tukey's honestly significant difference (HSD) test. MSEs and $p$ values are presented for all $F_{\mathrm{s}}$ greater than 1 , and $\eta_{\mathrm{p}}^{2}$ (a measure of effect size) is given for all significant main effects and interactions.

\section{Results}

\section{Conditioned responding}

Training. All six groups rapidly acquired conditioned responding (see Figure 2). It should be noted that it is difficult to draw firm conclusions from the compound training phase. Not only did different groups experience different physical stimuli, but also in groups $\mathrm{Nf} / \mathrm{Lv}$ and $\mathrm{Nv} / \mathrm{Lf}$, for which one of the CSs was fixed and the other variable, the period for which they overlapped would have been on average shorter than $15 \mathrm{~s}$. As a consequence, response rates during the noise/light compound in these groups would not be strictly 


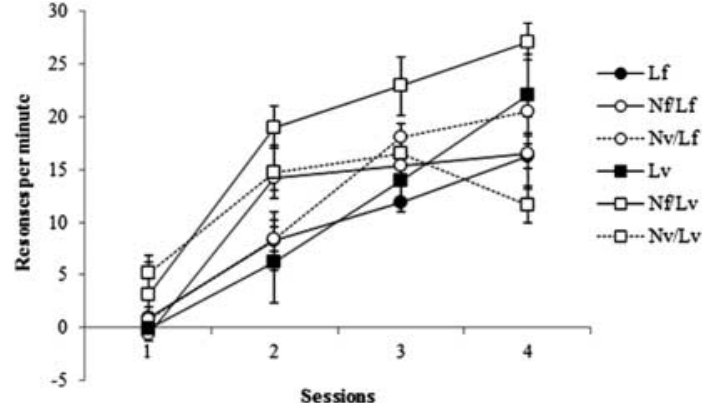

Figure 2. Group mean corrected response rates during the light for groups $L f$ and $L v$, and during the noisellight compound for groups $N f / L f, N f / L v, N v / L f$, and $N v / L v$ ( $\pm 1 \mathrm{SE}$; where $L=$ light, $N$ $=$ noise, $f=$ fixed, and $v=$ variable) in each of the four training sessions of Experiment 1.

comparable to those in groups $\mathrm{Nf} / \mathrm{Lf}$ and $\mathrm{Nv} / \mathrm{Lv}$, for whom the average recording period on each trial would have been $15 \mathrm{~s}$.

ANOVA performed on the corrected scores, with overshadowing CS (noise absent, fixed, or variable), target CS (light fixed or variable), and session as factors revealed a significant three-way interaction, $F(6,54)=4.76, p<.001, M S E=$ $14.24, \eta_{\mathrm{p}}^{2}=.35$; there was also an interaction between session and overshadowing CS, $F(6$, $54)=3.60, p=.004, M S E=14.24, \eta_{\mathrm{p}}^{2}=.29$, and significant effects of target, overshadowing CS, and session, $F(1,18)=5.41, p=.032, M S E=$ $31.18, \quad \eta_{\mathrm{p}}^{2}=.23 ; \quad F(2, \quad 18)=5.86, \quad p=.011$, $M S E=31.18, \eta_{\mathrm{p}}^{2}=.39 ;$ and $F(3,54)=99.71$, $p<.001, M S E=14.24, \quad \eta_{\mathrm{p}}^{2}=.85$, respectively. Nothing else was significant, largest $F(2,18)=$ $3.18, p=.066, M S E=31.18$. To examine the three-way interaction, separate ANOVAs were conducted on the data from the three groups for each target CS condition (light fixed or variable), with overshadowing CS and session as factors. For the groups trained with a fixed-duration light this revealed only a significant effect of sessions, $F(3, \quad 27)=55.1, \quad p<.001, \quad M S E=12.75$, $\eta_{\mathrm{p}}^{2}=.86$; the effect of overshadowing CS and the interaction were not significant, $F<1$ and $F(6$, $27)=2.07, p=.09, M S E=12.75$, respectively. The corresponding analysis of the data from the groups trained with a variable CS revealed a significant interaction, $F(6,27)=5.89, p<.001$,
Table 1. Group mean response rates during the pre-CS periods in the four training sessions of Experiment 1 and Experiment 2

AQ33

\begin{tabular}{|c|c|c|c|c|c|}
\hline \multirow[b]{2}{*}{ Experiment } & \multirow[b]{2}{*}{ Condition } & \multicolumn{4}{|c|}{ Session } \\
\hline & & 1 & 2 & 3 & 4 \\
\hline \multirow[t]{6}{*}{ Experiment 1} & Lf & 5.9 & 10.3 & 7.6 & 2.5 \\
\hline & $\mathrm{Lv}$ & 7.2 & 9.1 & 9.0 & 4.8 \\
\hline & $\mathrm{Nf} / \mathrm{Lf}$ & 6.5 & 7.6 & 2.9 & 1.7 \\
\hline & $\mathrm{Nf} / \mathrm{Lv}$ & 7.2 & 8.5 & 3.2 & 2.8 \\
\hline & $\mathrm{Nv} / \mathrm{Lf}$ & 5.4 & 9.4 & 3.2 & 3.2 \\
\hline & $\mathrm{Nv} / \mathrm{Lv}$ & 6.0 & 10.5 & 7.3 & 7.4 \\
\hline \multirow[t]{6}{*}{ Experiment 2} & Lf & 6.8 & 8.2 & 4.0 & 2.0 \\
\hline & $\mathrm{Lv}$ & 4.7 & 8.3 & 4.0 & 4.0 \\
\hline & $\mathrm{Nf} / \mathrm{Lf}$ & 3.3 & 3.2 & 0.8 & 1.0 \\
\hline & $\mathrm{Nf} / \mathrm{Lv}$ & 4.3 & 2.9 & 0.8 & 1.2 \\
\hline & Nv/Lf & 5.4 & 3.9 & 1.4 & 1.3 \\
\hline & $\mathrm{Nv} / \mathrm{Lv}$ & 5.0 & 5.6 & 4.7 & 2.6 \\
\hline
\end{tabular}

Note: $\mathrm{CS}=$ conditioned stimulus; $\mathrm{L}=$ light; $\mathrm{N}=$ noise; $\mathrm{f}=$ fixed; and $\mathrm{v}=$ variable.

$M S E=15.73, \eta_{\mathrm{p}}^{2}=.57$. The three overshadowing CS conditions differed on Sessions 2, 3, and 4, smallest $F(2,36)=4.77, p=.015, M S E=18.01$ for Session 3; Tukey's tests revealed that group $\mathrm{Nf} / \mathrm{Lv}$ responded more than group $\mathrm{Lv}$ on Sessions 2 and 3, $p<.01$ and $p<.05$, respectively, and group $\mathrm{Nv} / \mathrm{Lv}$ less than groups $\mathrm{Lv}$ and $\mathrm{Nf} / \mathrm{Lv}$ on Session $4, p<.05$ and $p<.01$, respectively; in addition, group $\mathrm{Lv}$ responded less than group $\mathrm{Nv} / \mathrm{Lv}$ on Session 2, $p<.05$. Thus when the target light was fixed, all three groups appear to acquire the $\mathrm{CR}$ at similar rates, but differences were evident when the target CS was variable, the most consistent of these being the relatively higher response rates in group $\mathrm{Nf} / \mathrm{Lv}$.

The group mean pre-CS scores for Sessions 1-4 are shown in Table 1. ANOVA with target CS, overshadowing CS, and sessions as factors revealed a main effect of target CS, $F(1,18)=5.16$, $p=.036, \quad M S E=9.21, \quad \eta_{\mathrm{p}}^{2}=.22 ; \quad$ background responding was slightly but consistently higher in animals trained with a variable light $(\mathrm{Lv}, \mathrm{Nf} / \mathrm{Lv}$, and $\mathrm{Nv} / \mathrm{Lv}$ ). It is possible that the higher response rates seen in groups trained with the variable light indicates less effective overshadowing of the context by this stimulus. There was also a main effect of overshadowing CS, $F(2,18)=3.75$, 
$p=.043, \quad M S E=9.20, \quad \eta_{\mathrm{p}}^{2}=.29, \quad$ respectively, which interacted significantly with sessions, $F(6$, $54)=3.90, \quad p=.003, \quad M S E=4.26, \quad \eta_{\mathrm{p}}^{2}=.30$; simple main effects revealed an effect of overshadowing CS on Sessions 3 and 4, $F(2,72)=9.84$, $p=.0002$, and $F(2,72)=3.48, \quad p=.036$, $M S E=5.49$, for Sessions 3 and 4, respectively, and Tukey's test showed that in Session 3 the control groups responded more than both fixed and variable groups, $p<.01$ and $p<.05$, respectively, while on Session 4 the fixed groups responded more than the variable groups, $p<.01$. There was also a significant effect of sessions, $F(3,54)=$ 29.5, $\quad p<.001, \quad M S E=4.26, \quad \eta_{\mathrm{p}}^{2}=.62$, but nothing else was significant, largest $F(3,54)=$ 1.44, $p=.24, M S E=4.26$.

Finally, the mean duration of the variable noise over these four training sessions was $14.05 \mathrm{~s}$ $(S E M=2.16 \mathrm{~s})$; these values did not differ from the target value of $15 \mathrm{~s}$ on any session.

Test.. All the test trials were of a fixed $15 \mathrm{~s}$ in duration.

Light: Corrected scores. The mean corrected rates of responding to the light are shown in the top panel of Figure 3. Responding to the light was clearly lower in the overshadowing than in the control groups, suggesting that overshadowing had occurred-but it was less clear that the overshadowing effect differed among the groups: Although responding was numerically greater in group $\mathrm{Nf} / \mathrm{Lf}$ than in group $\mathrm{Nv} / \mathrm{Lf}$, responding in groups $\mathrm{Nf} / \mathrm{Lv}$ and $\mathrm{Nv} / \mathrm{Lv}$ was very similar. ANOVA confirmed this description of the data, revealing a significant main effect of overshadowing $\mathrm{CS}, F(2,18)=22.25, p<.001, M S E=25.70$, $\eta_{\mathrm{p}}^{2}=.71 ;$ nothing else was significant, $F_{\mathrm{S}}<1$. However, Tukey's test revealed that although responding to the light was significantly higher in the control groups than in both overshadowing groups, $p$ s $<.01$, responding to the light in the overshadowing groups did not differ. Thus there was evidence that overshadowing had occurred, but not that it differed in magnitude among the various conditions on this measure.
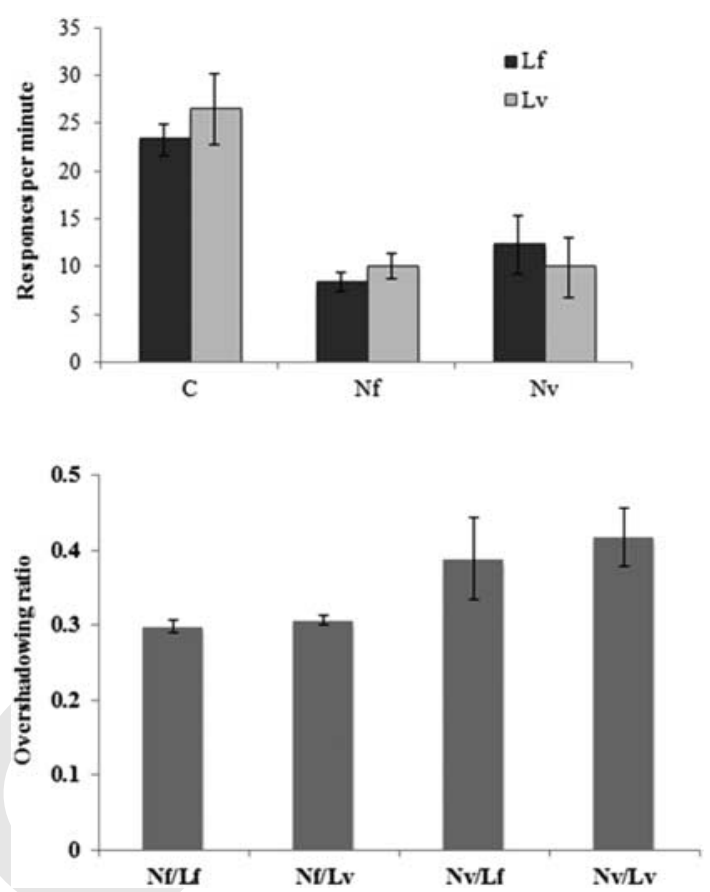

Figure 3. Test sessions of Experiment 1: Top panel: Group mean corrected response rates during the light test trials. Bottom panel: Group mean overshadowing ratios for the overshadowing groups. $C$ (control), $N f$, and $N v$ refer to whether the overshadowing stimulus was absent, fixed, or variable, and Lf and Lv to whether the target conditioned stimulus (CS) was fixed or variable $(L=$ light, $N=$ noise). Error bars show standard error of the mean.

The mean pre-CS rates, pooled over all trial types, were $3.86,1.21$, and 1.23 responses per minute (rpm) for groups Lf, Nf/Lf, and Nv/Lf, and $4.79,1.11$, and $4.86 \mathrm{rpm}$ for groups $\mathrm{Lv}, \mathrm{Nf} /$ $\mathrm{Lv}$, and $\mathrm{Nv} / \mathrm{Lv}$, respectively. ANOVA revealed main effects of target $\mathrm{CS}$, again indicating higher rates of background responding when the light was variable, $F(1,18)=6.06, p=.02, M S E=$ $0.219, \eta_{\mathrm{p}}^{2}=.25$, and of overshadowing CS, $F(2$, $18)=9.26, p=.002, M S E=0.219, \eta_{\mathrm{p}}^{2}=.51$; the interaction was not significant, $F(2,18)=3.39$, $p=.06, M S E=0.219$. Tukey's test revealed that pre-CS rates were higher in the control than in the fixed groups, $p=.01$.

\section{Light: Overshadowing ratio}

To examine differences among the overshadowing groups in a more sensitive manner, an 
overshadowing ratio was calculated using the mean uncorrected rates of responding on the noise/light test trials as a baseline. The resultant ratios are shown in the lower panel of Figure 3, and it is clear that overshadowing ratios were lower in groups $\mathrm{Nf} / \mathrm{Lf}$ and $\mathrm{Nf} / \mathrm{Lv}$ than in groups $\mathrm{Nv} / \mathrm{Lf}$ and $\mathrm{Nv} / \mathrm{Lv}$, an effect that was independent of the temporal distribution of the light. This pattern is consistent with the prediction that overshadowing would greater in groups trained with a fixed-duration noise. ANOVA with overshadowing CS (noise fixed or variable) and target CS (light fixed or variable) as factors confirmed that there was a main effect of overshadowing $\mathrm{CS}, F(1,12)=$ 5.41, $p<.04, M S E=.007, \eta_{\mathrm{p}}^{2}=.31$, but no effect of target or interaction, $F_{\mathrm{S}}<1$. Thus the overshadowing ratios demonstrated a significantly greater overshadowing effect when the overshadowing stimulus was fixed than when it was variable.

The uncorrected rates of responding during the noise/light test trials were 23.4, 25.3, 20, and 20.7 rpm for groups $\mathrm{Nf} / \mathrm{Lf}, \mathrm{Nf} / \mathrm{Lv}, \mathrm{Nv} / \mathrm{Lf}$, and $\mathrm{Nv} / \mathrm{Lv}$, respectively, and did not differ-ANOVA with overshadowing CS and target revealed nothing significant, largest $F(1,12)=1.57, p=.24, M S E=$ 40.89 .

\section{Timing of the noise}

The mean response rates in each 3-s bin of the final training session were collapsed over the two groups trained with a fixed noise, Nf/Lf and $\mathrm{Nf} / \mathrm{Lv}$, and those trained with a variable noise, $\mathrm{Nv} / \mathrm{Lf}$ and $\mathrm{Nv} /$ $\mathrm{Lv}$; the resulting data are presented in Figure 4. There appeared to be a gradual increase of responding over the course of the CS in the groups trained with a fixed noise, but not in those trained with a variable noise. ANOVA with overshadowing CS (fixed or variable) and bin as factors revealed no effect of overshadowing $\mathrm{CS}, F<1$, but a significant effect of bin, $F(4,56)=12.08, p<.001, M S E=$ $33.11, \eta_{\mathrm{p}}^{2}=.46$, and a significant interaction between these two factors, $F(4,56)=5.28$, $p=.001, \quad M S E=33.11, \quad \eta_{\mathrm{p}}^{2}=.27 ; \quad$ however, responding in the two overshadowing CS conditions did not differ on any bin, largest $F(1$, $70)=3.34, p=.073, M S E=66.16$ for $\operatorname{Bin} 4$.

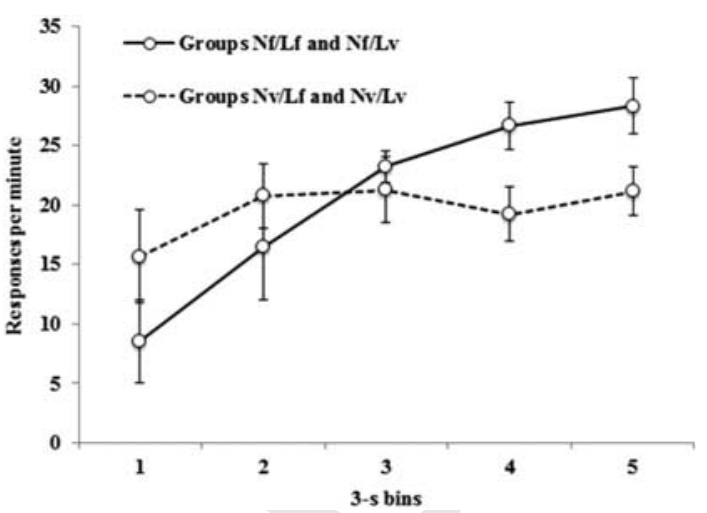

Figure 4. Group mean responses per minute ( $\pm 1 \mathrm{SE}$ ) over the course of the fixed- (groups $N f / L f$ and $N f / L v$ ) and variableduration (groups $N v / L f$ and $N v / L v$ ) noise during the compound trials of the final training session of Experiment 1. L = light, $N$ $=$ noise, $f=$ fixed, and $v=$ variable $\square$. The data are presented in 3-s bins.

$\mathrm{AQ} 28$

There was also a significant effect of bin for the fixed, $F(4,56)=16.03, p<.001, M S E=33.11$, but not the variable overshadowing CS condition, $F(4,56)=1.33, \quad p=.27, \quad M S E=33.11$. The mean slope for the fixed and variable conditions was .61 and .16, respectively, and these scores differed significantly, $F(1,15)=7.54, p=.016$, $M S E=.35, \eta_{\mathrm{p}}^{2}=.35$; the former value differed significantly from zero, $p<.001$, but the latter did not, $p=.233$. This suggests that the animals showed patterns of responding over the noise CSs appropriate to their temporal distributions (cf. Kirkpatrick \& Church, 1998).

\section{Discussion}

The results of this experiment suggest that a fixed stimulus overshadows more effectively than a variable one: Conditioned responding on the light test trials in groups $\mathrm{Nf} / \mathrm{Lf}$ and $\mathrm{Nf} / \mathrm{Lv}$ represented a lower proportion of responding during the noise/light compound than in groups $\mathrm{Nv} / \mathrm{Lf}$ and $\mathrm{Nv} / \mathrm{Lv}$; however, this difference was not evident in the corrected response rates to the light in the present experiment. Nonetheless, the difference in the overshadowing ratios is consistent with the suggestion that, although of the same mean duration, 
AQ20 fixed-duration CSs were better than cues whose $\curlywedge$ duration varies from trial to trial (Jennings et al., 2013).

Moreover, these findings rule out some potential alternative explanations. For example, Miller and colleagues proposed the temporal coding hypothesis (e.g., Blaisdell, Denniston, \& Miller, 1998), according to which the temporal relationship between the two events that are associated during a conditioning procedure is automatically encoded as part of the association and affects what may be learned. Although this theory does not fall into the class of trial-based associative models we set out to test, it predicts that cue competition will be maximal when both cues convey identical temporal information. Blaisdell et al. (1998) confirmed this prediction, demonstrating robust overshadowing only when the overshadowing cue had the same temporal relation to the US as the target, where temporal information referred to whether the CSs preceded the US, they followed it, or CS and US were coextensive (Blaisdell et al., 1998). If one extends the definition of temporal information to whether the CS is of fixed or variable duration, then the temporal coding hypothesis predicts better overshadowing when both cues are fixed, or both are of the same variable durations (e.g., both $5 \mathrm{~s}$ on one trial, and $3 \mathrm{~s}$ on another). This would predict greater overshadowing in group $\mathrm{Nf} / \mathrm{Lf}$ than in $\mathrm{Nv} / \mathrm{Lf}$, as we found-but also greater overshadowing in group $\mathrm{Nv} / \mathrm{Lv}$ than in group $\mathrm{Nf} / \mathrm{Lv}$, the opposite to what we observed. Thus the present findings cannot be explained in terms of the temporal coding hypothesis.

A second potential explanation of our results appeals to generalization decrement. In group Nf/ Lf, the light was never experienced in the absence of the noise, as the two cues overlapped perfectly, whereas in group $\mathrm{Nv} / \mathrm{Lf}$ the light was experienced alone on all trials on which the noise was shorter than $15 \mathrm{~s}$. This could result in more generalization decrement of the light at test in group Nf/Lfreducing responding and thus resulting in an apparently stronger overshadowing effect (cf. Kehoe, 1983). However, this account would also predict greater overshadowing in group $\mathrm{Nv} / \mathrm{Lv}$, in which noise and light were coextensive, than in group $\mathrm{Nf} / \mathrm{Lv}$, in which they were not-but the opposite pattern was observed. Thus these results cannot be explained in terms of generalization decrement (see also Jennings et al., 2007).

One issue with the present study concerns the ratio measure. In principle this technique is no different from the standard practice of correcting for rates of pre-CS responding, as it merely allows responding during the stimulus of interest to be corrected against a baseline measure of individual differences in response rates. Nonetheless, it would be more compelling if we could demonstrate our key differences using the less derived corrected response rate measure of responding to the light. Thus in Experiment 2 the intensity of the noise CS was slightly increased, with the hope of exaggerating overshadowing, and thus revealing differences in the response rate measure.

\section{EXPERIMENT 2}

Experiment 2 was formally identical to Experiment 1 , but with a few key differences. First, the intensity of the noise was increased to $75 \mathrm{~dB}$. Second, in Experiment 1 we demonstrated differences in the pattern of responding to the fixed- and variableduration overshadowing stimuli by examining behaviour to the noise during compound training trials. It would be helpful to have confirmation that animals would show similar behaviour to the noise when presented alone, to rule out the possibility that the pattern we observed was contaminated by the presence of the target light CS. Accordingly Experiment 2 incorporated probe trials with the noise during the training sessions, during which timing could be examined. Third, our account would predict higher response rates to the fixed than to the variable noise (cf. Jennings et al., 2013), but Experiment 1 did not examine responding to this stimulus. Thus in Experiment 2 responding to the noise alone was examined, both in the probe trials just described, and also by adding two sessions of test trials with the noise CS after the test of the light. The first test comprised compound training intermixed with 15-s fixed-duration test trials with the noise 
alone. The second comprised only noise trials, half of fixed duration and the remainder of variable duration, a procedure designed to equate generalization decrement between the training and test conditions for all animals.

\section{Method}

\section{Subjects}

Light test. The first testing phase was identical to that of the previous experiment. There was one session in this stage.

Noise test. The final two sessions were received only by the four overshadowing groups. The first comprised 25 compound trials, exactly as in the training phase, plus fifteen 15-s test trials-presentations of the noise, 10 of which were reinforced and the remaining five nonreinforced. These trials were delivered in blocks of eight trials-five compound trials and two reinforced and one nonreinforced noise trial—delivered in a semirandom order. The second comprised only test trials with the noise: Thus in this final session all animals received twenty 15 -s fixed-duration and 20 mean 15 -s variable-duration noise presentations; half of each trial type were followed by food, and the remainder were nonreinforced. In all other respects this test session was identical to the previous sessions.

\section{Data analysis}

This was identical to that of Experiment 1, except that timing data were also computed for the noise during the probe trials of the last conditioning sessions. In addition, the corrected response rates to the noise in the probe trials of the training sessions, as well as in the two test sessions, were also reported.

\section{Results}

\section{Conditioning responding}

Training. Group mean corrected scores from the four training sessions are shown in Figure 5; again there seemed to be evidence of overshadowing in all four overshadowing groups, but this appeared to be more profound in groups $\mathrm{Nf} / \mathrm{Lf}$ and $\mathrm{Nf} / \mathrm{Lv}$ trained with the fixed-duration noise. ANOVA with overshadowing CS (absent, fixed, or variable), target CS (fixed or variable), and session as factors revealed a significant main effect of session, $F(3,51)=96.98, p<.001, M S E=$ 16.52, $\eta_{\mathrm{p}}^{2}=.851$, and a significant interaction between overshadowing $\mathrm{CS}$ and session, $F(6$,

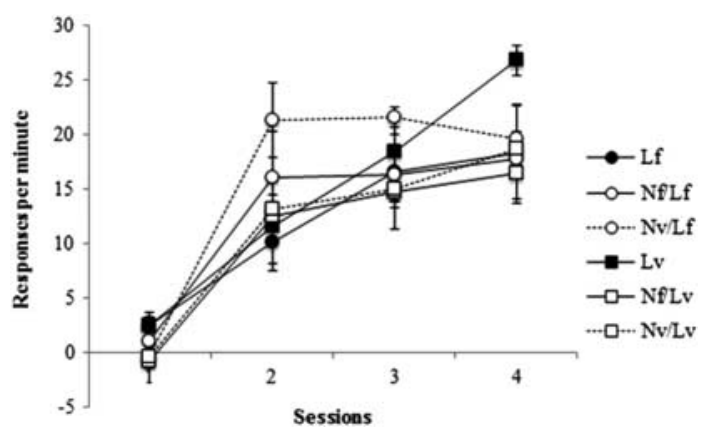

Figure 5. Group mean corrected response rates during the light for groups $L f$ and $L v$, and during the noisellight compound for groups $N f / L f, N f / L v, N v / L f$, and $N v / L v( \pm 1 \mathrm{SE}$; where $L=$ light, $N$ $=$ noise, $f=$ fixed, and $v=$ variable) in each of the four training sessions of Experiment 2.
AQ29 
$51)=2.66, \quad p=.025, \quad M S E=16.52, \quad \eta_{\mathrm{p}}^{2}=.24$. Nothing else was significant, largest $F(2,17)=$ 2.21, $p=.14, M S E=41.38$ for the overshadowing $\mathrm{CS} \times$ Target interaction. Exploration of the significant interaction between overshadowing CS and session revealed only a significant difference between the conditions on Session 2, $F(2,68)=$ 3.52, $p=.04, M S E=22.74$, but Tukey's tests did not reveal any differences between the three overshadowing CS conditions; there were no differences on any other session, largest $F(2,68)=$ 1.92, $p=.15, M S E=22.74$ for Session 4 .

This study also examined response rates to the noise in isolation on the probe trials; the corrected response rates on these trials are shown in top panel of Table 2. Response rates tended to be higher when the noise was fixed, and also when the light was fixed; ANOVA with target CS, overshadowing $\mathrm{CS}$, and sessions as factors revealed mean effects of all three, $F(1,12)=6.37, p=.03, M S E=17.42$, $\eta_{\mathrm{p}}^{2}=.35, F(1,12)=6.45, p=.03, M S E=17.42$, $\eta_{\mathrm{p}}^{2}=.35, \quad$ and $F(13, \quad 36)=16.23, \quad p<.001$, $M S E=27.72, \eta_{\mathrm{p}}^{2}=.58$. Nothing else was significant, largest $F(3,36)=2.37, p=.09, M S E=$ 27.72. Thus, far from the fixed-duration noise eliciting more conditioned responding than the variable, the opposite was the case.

AQ37

Table 2. Experiment 2: Group mean corrected response rates during the noise in the four training sessions, and during the second noise test as a function of test trial distribution

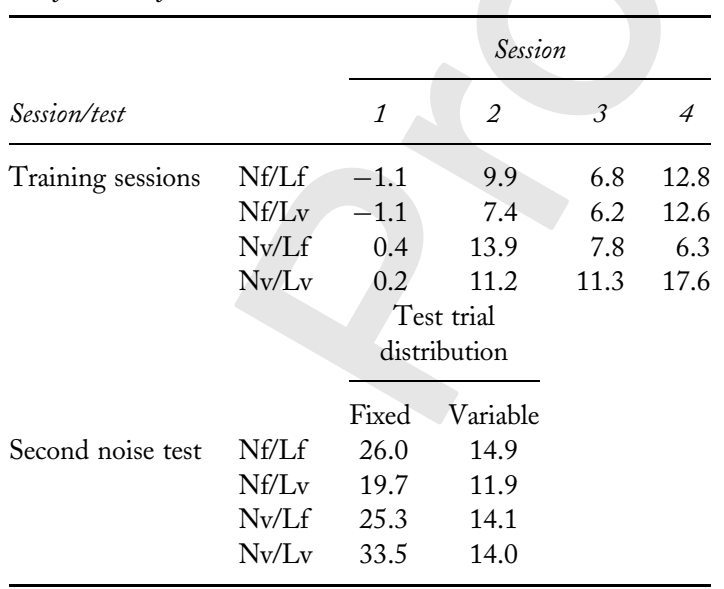

Note: $\mathrm{L}=$ light; $\mathrm{N}=$ noise; $\mathrm{f}=$ fixed; and $\mathrm{v}=$ variable.
The group mean pre-CS scores for Sessions 1-4 are shown in the lower panel of Table 1. ANOVA with target $\mathrm{CS}$, overshadowing $\mathrm{CS}$, and sessions as factors revealed a main effect of overshadowing CS, $F(2,17)=9.45, p=.002, M S E=7.23, \eta_{\mathrm{p}}^{2}=.53$, and also a significant main effect of session, $F(3$, $51)=17.36, \quad p<.001, \quad M S E=3.57, \quad \eta_{\mathrm{p}}^{2}=.51$; nothing else was significant, largest $F(6,51)=$ $1.53, p=.19, M S E=3.57$. Tukey tests were used to explore the main effect of condition and revealed that rates of pre-CS responding were higher in the control than in the fixed condition, $p<.01$.

Finally, the mean duration of the variable noise over these four training sessions was $13.81 \mathrm{~s}$ $(S E M=2.06 \mathrm{~s})$; these values did not differ from the target value of $15 \mathrm{~s}$ on any session.

\section{Test}

Light: Corrected scores. The mean corrected rates of responding to the light are shown in the top panel of Figure 6. There was not only a marked overshadowing effect, but it appeared more profound with the fixed overshadowing stimulus. ANOVA with overshadowing CS and target as factors revealed a significant main effect of overshadowing CS, $F(2$, $17)=14.82, p<.001, M S E=38.71, \eta_{\mathrm{p}}^{2}=.635$; nothing else was significant, $F_{\mathrm{S}}<1$. Tukey's test revealed that responding to the light was significantly lower in the fixed groups than in both the control and the variable conditions $p$ s $<.01$. Thus there was evidence for overshadowing, but only in the fixed condition.

The mean pre-CS rates during this session were 2.3, 0.4, and $1.2 \mathrm{rpm}$ for groups Lf, $\mathrm{Nf} / \mathrm{Lf}$, and Nv/ $\mathrm{Lf}$, and 1.7, 0.6, and $1.5 \mathrm{rpm}$ for groups $\mathrm{Lv}, \mathrm{Nf} / \mathrm{Lv}$, and $\mathrm{Nv} / \mathrm{Lv}$, respectively. ANOVA revealed only a main effect of overshadowing $\mathrm{CS}, F(2,17)=4.1$, $p=.04, M S E=0.97, \eta_{\mathrm{p}}^{2}=.33$; nothing else was significant, $F_{\mathrm{S}}<1$. Tukey's test revealed that preCS rates were higher in the control than in the fixed groups, $p<.05$-although, as in the previous experiment, these differences were extremely small relative to rates of responding during the CS.

\section{Light}

Overshadowing ratio. The overshadowing ratios are shown in the lower panel of Figure 6, where it is 


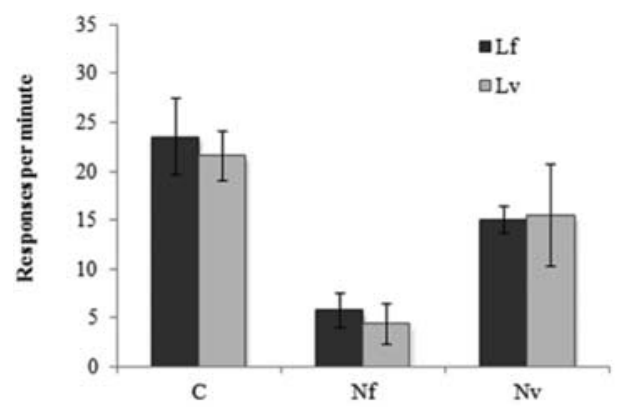

600

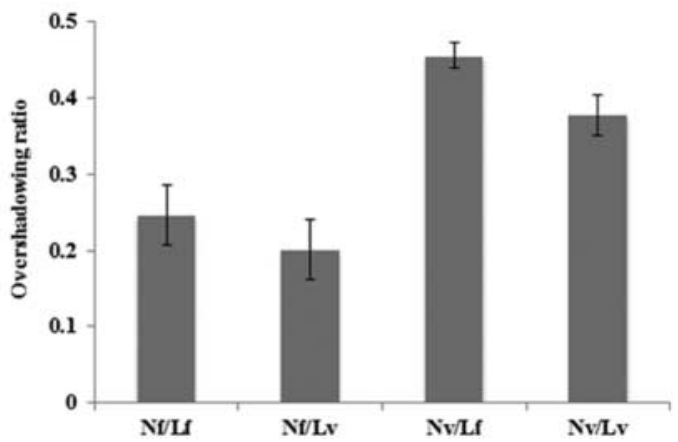

Figure 6. Test sessions of Experiment 2: Top panel: Group mean corrected response rates during the light test trials. Bottom panel: Group mean overshadowing ratios for the overshadowing groups. $C$ (control), $N$ f, and $N v$ refer to whether the overshadowing stimulus was absent, fixed, or variable, and $L f$ and $L v$ to whether the target conditioned stimulus (CS) was fixed or variable $(L=$ light, $N=$ noise). Error bars show standard error of the mean.

evident that greater overshadowing was produced by a fixed- than a variable-duration light. ANOVA with overshadowing CS and target as factors revealed a significant main effect of overshadowing CS, $F(1,12)=9.14, p=.01, M S E=.016$, $\eta_{\mathrm{p}}^{2}=.43$. Thus in the present study this measure yielded the same result as the corrected response rates to the light-greater overshadowing by the fixed-duration stimulus.

The mean uncorrected rates of responding during the noise/light test trials, which were used as a baseline for the overshadowing measure, were $18.8,17.4,19.4$, and $24.6 \mathrm{rpm}$ in groups $\mathrm{Nf} / \mathrm{Lf}$, $\mathrm{Nf} / \mathrm{Lv}, \mathrm{Nv} / \mathrm{Lf}$, and $\mathrm{Nv} / \mathrm{Lv}$, respectively, and did not differ-ANOVA with overshadowing CS and target as factors revealed nothing significant, largest $F(1,12)=3.26, p=.1, M S E=18.63$ for the effect of target CS.

Timing: Training compound trials. The distribution of responding over the course of the noise, computed over five 3-s bins, during the compound trials of the final training session is shown in Figure 7 (top panel), pooled over groups $\mathrm{Nf} / \mathrm{Lf}$ and $\mathrm{Nf} / \mathrm{Lv}$, and over groups $\mathrm{Nv} / \mathrm{Lf}$ and $\mathrm{Nv} / \mathrm{Lv}$. As in Experiment 1, responding appeared to increase gradually over the course of the CS in the fixed groups, but not in the variable groups; there were also slightly higher rates at the end of the CS in the fixed condition. ANOVA with overshadowing CS (fixed or variable) and bin as factors revealed no effect of overshadowing CS, $F(1$, $14)=1.05, p=.32, M S E=180.1$, but a significant effect of bin, $F(4,56)=6.84, p<.001$, $M S E=24.57, \eta_{\mathrm{p}}^{2}=.33$, and a significant interaction, $F(4,56)=10.24, p=.001, M S E=24.57$, $\eta_{\mathrm{p}}^{2}=.43$; responding in the two overshadowing CS conditions differed significantly in the first bin, $F(1,70)=17.4, p=.001, M S E=55.68$, although not on any other bin, largest $F(1,70)=$ 2.26, $p=.14, M S E=55.68$ for Bin 2. There was also a significant main effect of bin for the fixed but not the variable condition, $F(4,56)=16.45$, $p<.001, M S E=24.57$, and $F<1$, respectively. The mean slope was .58 and -.07 for the fixed and variable conditions respectively, and these scores differed significantly, $F(1,15)=19.31$, $p=.001, M S E=.35, \eta_{\mathrm{p}}^{2}=.35$; the former value differed significantly from zero, $p<.001$, whereas the latter did not, $p=.57$. Thus animals again clearly timed the noise in the fixed condition.

Timing: Training noise probe trials. Responding to the noise alone during the probe trials (averaged across sessions) is shown in Figure 7 (lower panel). ANOVA revealed no effect of overshadowing $\mathrm{CS}, F<1$, but a significant main effect of sessions, $F(4,56)=4.55, p=.003, M S E=33.16$, $\eta_{\mathrm{p}}^{2}=.25$, and also a significant interaction between overshadowing CS and bin, $F(4,56)=$ $3.73, p=.009, M S E=12.48, \eta_{\mathrm{p}}^{2}=.21$; the overshadowing CS conditions differed on Bin 1, $F(1$, $70)=4.89, p=.03, M S E=99$, and there was an 
AQ31
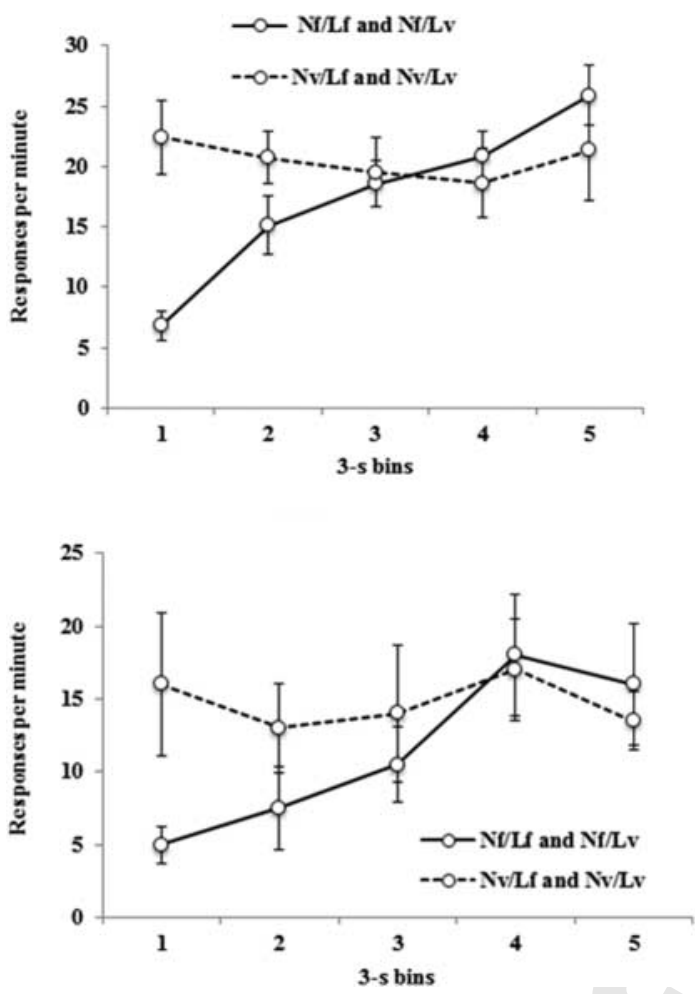

Figure 7. Group mean responses per minute ( $\pm 1 \mathrm{SE}$ ) over the course of the fixed- (groups $N f / L f$ and $N f / L v$ ) and variableduration (groups $N v / L f$ and $N v / L v$ ) noise in Experiment 2. $L=$ light, $N=$ noise, $f=$ fixed, and $v=$ variable. The data are presented in 3-s bins. Top panel: Data from the compound trials of the final training session. Bottom panel: Data from the probe trials of the final training session.

effect of bins in the fixed but not the variable conditions, $F(4,56)=7.34, p=.0001, M S E=33.16$, and $F<1$, respectively. The mean slopes for fixed and variable conditions were 0.52 and 0.09 , respectively, and differed significantly, $F(1,15)=$ 14.98, $p=.002, \quad M S E=0.051, \quad \eta_{\mathrm{p}}^{2}=.52 ;$ the former differed from zero whereas the latter did not, $p<.001$ and $p=.37$, respectively. Thus the pattern of responding on the probe trials was essentially similar to that evident during the compound trials.

\section{Noise test}

No differences in responding to the noise as a function of experimental condition were observed in either test:
Test 1: The mean corrected response rates for the test trials were $12.5,12.8,14.8$, and $18.9 \mathrm{rpm}$ for groups $\mathrm{Nf} / \mathrm{Lf}, \mathrm{Nf} / \mathrm{Lv}, \mathrm{Nv} / \mathrm{Lf}$, and $\mathrm{Nv} / \mathrm{Lv}$, respectively, and these scores did not differ, largest $F(1$, $12)=2.01, p=.18, M S E=35.1$. Pre-CS scores for this session were $0.93,0.8,2.1$, and $2.6 \mathrm{rpm}$ for groups $\mathrm{Nf} / \mathrm{Lf}, \mathrm{Nf} / \mathrm{Lv}, \mathrm{Nv} / \mathrm{Lf}$, and $\mathrm{Nv} / \mathrm{Lv}$, respectively; ANOVA revealed a significant main effect of overshadowing CS, $F(1,12)=13.88, p=.003$, $M S E=0.62, \eta_{\mathrm{p}}^{2}=.54$, indicating higher background responding in the groups trained with a variable noise. Nothing else was significant, $F_{\mathrm{s}}<1$.

Test 2: The mean corrected response rates are shown in Table 2 (lower panel). Responding was substantially higher on test trials that had a fixed duration, regardless of group: ANOVA with overshadowing CS, target CS, and test trial distribution (fixed or variable) revealed a significant effect of test trial distribution, $F(1,12)=28.08, \quad p<.001$, $M S E=44.10, \eta_{\mathrm{p}}^{2}=.70$; nothing else was significant, largest $F(1,12)=1.58, p=.23, M S E=$ 44.1. Mean pre-CS scores were 2.83 .4 , 4.3, and $3.5 \mathrm{rpm}$ for groups $\mathrm{Nf} / \mathrm{Lv}, \mathrm{Nv} / \mathrm{Lv}, \mathrm{Nf} / \mathrm{Lf}$, and Nv/Lf, respectively, and did not differ, $F_{\mathrm{S}}<1$.

\section{Discussion}

The results of this experiment replicate those of Experiment 1-better overshadowing by fixedthan by variable-duration cues-with the more direct, response rate measure as well as with the overshadowing ratio employed in Experiment 1. It seems likely that this was due to the increase in noise intensity exaggerating the overshadowing effect in the fixed condition: Comparing the lower panels of Figures 3 and 6 suggests that the overshadowing ratios were lower in the present experiment than in Experiment 1. Thus, although the degree of overshadowing in the variable condition was roughly constant, that in the fixed condition appeared to be enhanced, which is consistent with this interpretation.

As in Experiment 1, there was also evidence that by the end of compound training the animals were responding differentially over the course of the fixed- and variable-duration noise; when the noise was fixed responding increased gradually over the 
course of the CS, whereas when it was variable responding remained constant as the stimulus progressed. Moreover, this pattern was just as evident on the compound trials as on the probe trials with the noise alone, confirming that the presence of the light was not contaminating our observations. The study was less successful in revealing greater levels of conditioned responding to the noise when it was of fixed duration: In neither test was there any evidence for any difference in response rate to the noise according to whether it was of fixed or variable duration during training. Indeed, during the probe trials of the training sessions, animals in groups $\mathrm{Nv} / \mathrm{Lf}$ and $\mathrm{Nv} / \mathrm{Lv}$ actually responded more than groups $\mathrm{Nf} / \mathrm{Lf}$ and $\mathrm{Nf} / \mathrm{Lv}-$ although the failure to observe this effect in either test session raises doubts about the reliability of this finding. Nonetheless, our hypothesis would predict higher associative strength during the fixed-duration CS, and so at face value the failure to observe this is inconsistent with our suggestion.

There are, nonetheless, a number of potential reasons for this apparent discrepancy. First, our pilot work suggests that the parameters used in these experiments are not conducive to showing the difference in responding to fixed- and variable-duration cues that was shown by Jennings et al. (2013). We conducted two almost identical experiments very similar to those reported here, using noises of differing intensities. When the noise was of a higher intensity it supported significantly greater conditioned responding when it was of a fixed duration, consistent with our predictions - but overshadowing was too profound for any differences in the level of overshadowing to be detected. In contrast, with a lower intensity noise differences in overshadowing were seen, but differences in responding to the noise were no longer detectable. Thus it may be that the parameters conducive to observing graded overshadowing are not those best suited to observing differences in conditioning to the overshadowing stimulus. Second, the 15-s duration of the stimuli used here was much shorter than the 30-s or 60-s CSs employed by Jennings et al. (2013). As it is well established that factors other than associative strength, such as arousal and CS intensity, can also influence

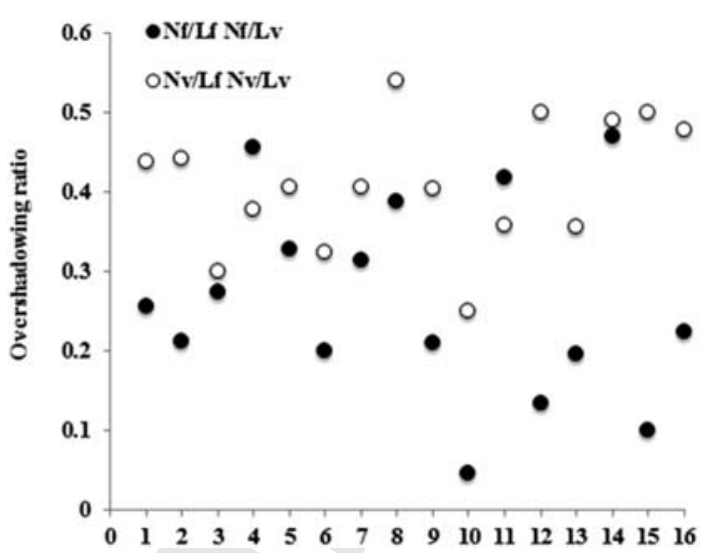

Figure 8. Scatter plot of individual overshadowing ratios for the light in each subject of groups $N f / L f$ and $N f / L v$ and groups $N v / L f$ and $N v / L v$ in the two experiments. $L=$ light, $N=$ noise, $f=$ fixed, and $v=$ variable.

CR performance (e.g., Hull, 1943), it is possible that, with these shorter stimuli, factors other than associative strength, such as the arousal induced by CS onset, have a greater influence on performance than with longer CSs. Indeed, to use overshadowing to obtain a measure of associative strength that did not rely solely on conditioned responding was the rationale underlying the present studies. Considerations of this type could in principle explain the pattern of responding to the noise observed in the present studies-as well as the fact that no clear difference in responding to the fixed- and variable-duration light was observed in our control groups, which we would also anticipate.

Finally, as noted in the introduction, the explanation of overshadowing offered by RET is that it is all or nothing, and not a graded effect. We took the opportunity to examine the data from the individual animals, in order to evaluate this prediction, we have plotted the overshadowing ratios from the individual animals. These data may be seen in Figure 8, and there is little indication that overshadowing is an all-or-nothing phenomenon.

\section{GENERAL DISCUSSION}

In both the experiments reported above, a fixedduration stimulus produced more overshadowing 
than a variable CS with the same mean duration, regardless of the distribution form-fixed or variable- of the overshadowed CS. We noted above that many trial-based theories predict that an overshadowing stimulus that can acquire associative strength more effectively will also produce a more profound overshadowing effect. Thus our findings are consistent with the suggestion that fixed-duration stimuli acquire associative strength more effectively than their variable counterparts. In this respect these data are consistent with the findings reported by Jennings et al. (2013) that fixed-duration CSs support more conditioned responding -but using a measure of associative strength other than strength of the conditioned response.

Time-accumulation models do not have the theoretical framework to explain differences in acquisition of associative strength by fixed- and variable-duration cues, as they would regard such stimuli as functionally equivalent if their mean duration is matched. In contrast, trial-based models, despite typically neglecting a conceptualization of temporal cues, have the theoretical framework to explain effects of this type. One very casual example of how fixed cues might condition better than variable cues was given in the introduction; however, the same prediction can be generated by a trial-based model that provides a more formal conceptualization of a stimulus's temporal properties. For example, the CSC version of the temporal difference (TD) model treats the $\mathrm{CS}$ as a series of temporally ordered components that acquire associative strength $(\mathrm{V})$ independently (Sutton $\&$ Barto, 1987; cf. Moore et al., 1998). The final component, $\mathrm{CS}_{\mathrm{n}}$, conditions based on the error it has predicting the US, but the strength of that immediately preceding it, $\mathrm{CS}_{n-1}$, changes according to the mismatch between its own $\mathrm{V}$ and the $\mathrm{V}$ of the final component, and so on. $\mathrm{V}$ accruing to successive units is determined by a parameter gamma $(\gamma)$, so that if $\mathrm{CS}_{\mathrm{n}}$ acquires $\mathrm{V}$ of 1 unit, $\mathrm{CS}_{n-1}$ will acquire this strength discounted by $\gamma-0.9$ units; $\mathrm{CS}_{n-2}$ will acquire $\mathrm{CS}_{n-1}$ 's strength discounted by $\gamma-0.81$ units; and so on. Learning during successive units is thus modulated by two parameters: a discount factor-gamma $(\gamma)$ - that results in an exponential decay with time, and an eligibility trace that grows and declines for each CS component according to a constant, delta. Low delta values produce a rapid decay and curtailed conditioning; high values of gamma result in more conditioning to CS components earlier in the CS.

These assumptions feature in a recent computational model, SSCC TD (Mondragón, Gray, Alonso, Bonardi, \& Jennings, 2014), which incorporates the basic assumptions of TD and extends it to stimulus configurations. SSCC TD also computes total CS associative strength to mirror the single predictive value of the CS generated by trial-based theories, by averaging each individual component's associative strength over all the components, and estimates the total CR from this value (Gray, Alonso, Mondragón, \& Fernández, 2012). Importantly, the model has successfully simulated Jennings et al.'s (2013) findings: A fixed CS gains more associative strength because each of its time-linked elements can reach asymptote. In contrast, although a variable CS comprises the same average number of time steps, many of its elements will be contiguous with the US on some trials, on which they gain $\mathrm{V}$, but distant from the US on others, on which they overpredict US occurrence, and lose $V$. This ensures that elements comprising variable-duration stimuli never reach a stable asymptotic value. Thus, unlike the elements comprising a fixed-duration CS, the increase in associative strength of successive elements of a variable-duration CS is not constant over time, but varies depending on the order and length of successive trials. SSCC TD could also simulate the results reported here. Thus this interpretation of the present findings is much more easily accommodated by a trial-based approach.

A further problem for a time-accumulation model like RET is that it proposes that overshadowing is based on a decision process whereby responding is confined to the physically most salient cue (Gallistel \& Gibbon, 2000). Thus RET could only explain these results by making the additional assumption that fixed-duration $\mathrm{CSs}$ are more salient than variable CSs. Moreover, according to these accounts, overshadowing is based on a decision rule; in any one animal it either occurs or not-it is not a graded effect, as trial-based 
models predict. In our experiments, the overshadowing effect appeared to be graded; in this sense our findings are consistent with the trial-based view, and also with other reports in the literature (e.g., Kehoe, 1982; Thein et al., 2008; although see Balsam et al., 2010). Nonetheless, although current formulations of time-accumulation models have difficulty with these results, it may be possible for their assumptions about the relative salience of fixed and variable cues to be further developed in order to accommodate these findings.

In summary, it seems that the associative, trialbased models might have the edge over the time accumulation accounts in explaining our findings. But such approaches have their limitations. As noted above, there is a lawful relationship between the ratio of the CS and ITI duration and both the speed with which the $\mathrm{CR}$ is acquired and the rate of conditioned responding (e.g., Gibbon et al., 1977; Holland, 2000; Lattal, 1999;

AQ4 Terrace et al., 1975), and it is a challenge for $\downarrow$ trial-based theories to explain such effects (although see e.g., Bouton \& Sunsay, 2003; 790 Holland, 2000). Moreover, timing accuracy is governed by Weber's law, such that the variability in timing is proportional to the duration of the interval being timed. This follows directly from the timing mechanisms incorporated into timeaccumulation theories such as RET (Gallistel \& Gibbon, 2000). It is not yet clear how a trialbased account could begin to explain such regularities; thus, adapting themselves to accommodate such effects remains a significant challenge.

Finally, there is at least one alternative interpretation of our results, which appeals to the notion of associability. Trial-based theories such as those proposed by Mackintosh (1975) and Pearce and Hall (1980) defined a property of a CS termed associability that can change with experience and determine the ease with which the CS can become associated with a US (Mackintosh, 1975; Pearce \& Hall, 1980). For example, latent inhibition training (Lubow \& Moore, 1959), in which a CS is presented without consequence prior to conditioning, retards acquisition of the $\mathrm{CR}$ compared to the case in which no preexposure occurred, theoretically because the CS's associability falls during the preexposure phase. Such nonreinforced preexposure can also influence the ability of a CS to overshadow another: By slowing the speed with which the preexposed CS conditions, the degree to which the overshadowed cue can acquire associative strength is increased (e.g., Carr, 1974). It is thus possible that fixed and variable cues differ not in their ability to reach asymptote, but in their associability, and that this produced the effects we observed; although it is not immediately obvious how any current theories could explain how associability could be influenced by the temporal properties of the stimulus in this way, this must remain a logical possibility. Equally, it is possible that a specific conceptualization of a CS's temporal properties could result in the prediction of greater overshadowing by a fixed CS, even without assuming that fixed and variable CSs acquire associative strength at different rates. But whether or not associability differences turn out to underlie our findings, our results imply that properties of a stimulus that vary trial to trial may have profound implications for learning - a conclusion that does not sit easily with time-accumulation models.

In conclusion, our results suggest that temporal information provided by the distribution form of the CS may play an important role in overshadowing, a result not easily explained by a range of timeaccumulation models. In contrast, an adapted realtime trial-based model of conditioning was able to account for the pattern of results we present (Mondragón et al., 2014; Sutton \& Barto, 1987). It appears that associative trial-based accounts of learning that are adapted to operate in real time might be best placed to offer a coherent account of the role of temporal CS factors on learning.

Original manuscript received 15 January 2014 Accepted revision received 23 June 2014

\section{REFERENCES}

Balsam, P. D., \& Gallistel, C. R. (2009). Temporal maps and informativeness in associative learning. Trends in Neurosciences, 32, 73-78. 
Balsam, P. D., Drew, M. R., \& Gallistel, C. R. (2010). Time and associative learning. Comparative Cognition and Behavior Reviews, 5, 1-22.

Blaisdell, A. P., Denniston, J. C., \& Miller, R. R. (1998). Temporal encoding as a determinant of overshadowing. Journal of Experimental Psychology: Animal Behavior Processes, 24, 72-83.

Bouton, M. E., \& Sunsay, C. (2003). Importance of trials versus accumulating time across trials in partially reinforced appetitive conditioning. Journal of Experimental Psychology: Animal Behavior Processes, 29, 62-77.

Carr, A. F. (1974). Latent inhibition and overshadowing in conditioned emotional response conditioning with rats. Journal of Comparative and Physiological Psychology, 86, 718-723.

Church, R. M., \& Broadbent, H. A. (1990). Alternative representations of time, number and rate. Cognition, $37,55-81$.

Cole, R. P., Barnet, R. C., \& Miller, R. R. (1995). Effect of relative stimulus validity: Learning or performance deficit?. Journal of Experimental Psychology: Animal Behavior Processes, 21, 293-303.

Denniston, J. C., Savastano, H. I., \& Miller, R. R. (2001). The extended comparator hypothesis: Learning by contiguity, responding by relative strength. In R. R. Mower \& S. B. Klein (Eds.), Handbook of Contemporary Learning Theories (pp. 65-117). Hillside: Erlbaum.

Gallistel, C. R., \& Gibbon, J. (2000). Time, rate and conditioning. Psychological Review, 107, 289-344.

Gibbon, J., Baldock, M. D., Locurto, C., Gold, L., \& Terrace, H. S. (1977). Trial and intertrial intervals in autoshaping. Journal of Experimental Psychology: Animal Behavior Processes, 3, 264-284.

Gibbon, J., \& Balsam, P. (1981). Spreading association in time. In L. C. Locurto, H. S. Terrace and J. Gibbon (Eds.), Autoshaping and conditioning theory (pp. 219-253). New York: Academic Press.

Gibbon, J., Church, R. M. \& Meck, W. H. (1984). Scalar timing in memory. In J. Gibbon and L. Allan (Eds.), Timing and Time Perception (pp. 5277). New York: New York Academy of Sciences.

Gray, J., Alonso, E., Mondragón, E. \& Fernández, A (2012). Temporal Difference Simulator (C) V.1 [Computer software]. London: CAL-R. http:// www.cal-r.org/index.php?id=TD-sim

Holland, P. C. (2000). Trial and intertrial interval durations in appetitive conditioning in rats. Animal Learning and Behavior, 28, 121-135.
Hull, C. L. (1943). Principles of Behavior. New York: Appleton Century Crofts.

Jennings, D., Bonardi, C., \& Kirkpatrick, K. (2007). Stimulus duration effects in overshadowing. Journal of Experimental Psychology: Animal Behavior Processes, 33, 464-475.

Jennings, D. J., Alonso, E., Mondragón, E., Franssen, M., \& Bonardi, C. (2013). The effect of stimulus duration distribution form on the acquisition and rate of conditioned responding. Journal of Experimental Psychology: Animal Behavior Processes, 39, 233-248.

Kamin, L. J. (1969). Predictability, surprise, attention and conditioning. In B. A.Campbell \& R. M. Church (Eds.), Punishment and aversive behavior (pp. 279-296). New York: Appleton-CenturyCrofts.

Kehoe, E. J. (1982). Overshadowing and summation in conditioning of the rabbit's nictitating membrane response to compound stimuli. Journal of Experimental Psychology: Animal Behavior Processes, 8, 313-328.

Kehoe, E. J. (1983). CS-US contiguity and CS intensity in conditioning of the rabbit's nictitating membrane response to serial compound stimuli. Journal of Experimental Psychology: Animal Behavior Processes, 9, 307-319.

Kirkpatrick, K., \& Church, R. M. (1998). Are separate theories of conditioning and timing necessary?. Behavioral Processes, 44, 163-182.

Kirkpatrick, K., \& Church, R. M. (2000). Stimulus and temporal cues in classical conditioning. Journal of Experimental Psychology: Animal Behavior Processes, 26, 206-219.

Kirkpatrick, K. (2002). Packet theory of conditioning and timing?. Behavioral Processes, 57, 89-106.

Kutlu, M. G., \& Schmajuk, N. A. (2012). Solving Pavlov's Puzzle: Attentional, associative and flexible configural mechanisms in classical conditioning. Learning and Behavior, 40, 269-291.

Lattal, K. M. (1999). Trial and intertrial durations in Pavlovian conditioning: Issues of learning and performance. Journal of Experimental Psychology: Animal Behavior Processes, 25, 433-450.

Lubow, R. E., \& Moore, A. U. (1959). Latent Inhibition - The effect of nonreinforced preexposure to the conditional stimulus. Journal of Comparative and Physiological Psychology, 52, 415-419.

Mackintosh, N. J. (1975). A theory of attention: Variation in the associability of stimuli with reinforcement. Psychological Review, 82, 276-298. 
Mackintosh, N. J. (1976). Overshadowing and stimulus intensity. Animal Learning and Behavior, 4, 186-192.

Mondragón, E., Gray, J., Alonso, E., Bonardi, C., \& Jennings, D. J. (2014). SSCC TD: A serial and sim-
860

AQ5

ᄉ ultaneous configural-cue compound stimuli representation for temporal difference learning. PLOS One, Under Review.

Moore, J. W., Choi, J., \& Brunzell, D. H. (1998). Predictive timing under temporal uncertainty: The TD model of the conditioned response. In D. Rosenbaum, A. C. E. Collyer (Eds.), Timing of Behavior: Neural, Computational, and Psychological Perspectives (pp. 3-34). Cambridge, MA: The MIT Press.

Pavlov, I. (1927). Conditioned reflexes. Oxford University Press.

Pearce, J. M. (1994). Similarity and discrimination: A selective review and a connectionist model. Psychological Review, 101, 587-607.

Pearce, J. M., Hall, G. (1980). A model for Pavlovian learning: Variations in the effectiveness of conditioned but not of unconditioned stimuli. Psychological Review, 87, 532-552.

Rescorla, R. A. (1988). Behavioral studies of Pavlovian conditioning. Annual Review of Neuroscience, 11, 329-352.

Rescorla, R. A., \& Wagner, A. R. (1972). A theory of Pavlovian conditioning: Variations in the

effectiveness of reinforcement. In A. H. Black \& W. F. Prokasy (Eds.), Classical conditioning: II. Theory and research (pp. 64-99). New York: Appleton-Century-Crofts.

Sutton, R. S., \& Barto, A. G. (1987). A temporal difference model of classical conditioning. Technical report TR 87-509.2. GTE Lab, Waltham, MA.

Tatham, T. A., \& Zurn, K. R. (1989). The Med-PC experimental apparatus programming system. Behavioral Research Methods, Instruments, and Computers, 21, 294-302.

Terrace, H. S., Gibbon, J., Farrell, L., \& Baldock, M. D. (1975). Temporal factors influencing the acquisition and maintenance of an autoshaped keypeck. Animal Learning and Behavior Processes, 3, 53-62.

Thein, T., Westbrook, R. F., \& Harris, J. A. (2008). How the associative strengths of stimuli combine in compound: Summation and overshadowing. Journal of Experimental Psychology: Animal Behavior Processes, 34, 155-166.

Vogel, E. H., Brandon, S. E., \& Wagner, A. R. (2002). Stimulus representation in SOP II: An application to inhibition of delay. Behavioral Processes, 110, 67-72.

Witnauer, J. E., Wojick, B. M., Polack, C. W., \& Miller, R. R. (2012). Performance factors in associative learning: Assessment of the sometimes competing retrieval model. Learning and Behavior, 40, 347-366. 